\title{
Cotejo entre variantes gráficas em manuscritos goianos dos séculos XVIII e XIX
}

\section{A comparison between graphic variants in manuscripts of Goias from the eighteenth and the nineteenth centuries}

\author{
Carolina Faleiros Felício* \\ Universidade Federal de Goiás, Catalão, GO, Brasil \\ Vanessa Regina Duarte Xavier ${ }^{* *}$ \\ Universidade Federal de Goiás, Catalão, GO, Brasil
}

\begin{abstract}
Resumo: A Filologia nos permite, através de critérios adequados, editar manuscritos antigos, conservando, em sua transcrição, o máximo possível, suas formas originais, o que possibilita, dentre vários estudos, o de caráter ortográfico. O corpus desta pesquisa é composto por quarenta cartas goianas redigidas entre os anos de 1751 e 1752, cujas edições fac-similar e semidiplomática estão disponíveis em Xavier (2012). Também faz parte do corpus a edição semidiplomática de um processo de partilha e inventário de bens de Catalão-Go, de 1851, a qual encontra-se em Pires (2015). O objetivo da pesquisa foi analisar variações gráficas presentes nos documentos referidos, comparando-as com as grafias presentes em instrumentos normatizadores da escrita da época, como os dicionários de Bluteau (1712-1728) e de Moraes Silva (1813), a fim de averiguar a consonância ou não entre elas. Primeiramente, foram coletados todos os vocábulos com variações gráficas, a saber, vocálicas e consonantais. Após a coleta, suas grafias foram verificadas nos dicionários mencionados e, em seguida, o mesmo foi feito com suas etimologias nos dicionários de Machado (1977) e Cunha (1986). Por fim, realizou-se a análise quantitativa e qualitativa das variantes, com base em obras de autores como Coutinho (1976), Williams (1975) e Teyssier (1997).
\end{abstract}

Palavras-chave: História da Língua Portuguesa. Variação gráfica. Filologia.

\begin{abstract}
Philology allows us, through appropriate criteria, to edit old manuscripts, preserving, in their transcription, as much as possible, their original forms, which enables, among several studies, the orthographic one. The corpus of this research is composed by forty letters from Goiás, written between the years of 1751 and 1752, whose editions fac-similar and semidiplomatic are available in Xavier (2012). It also makes part of the corpus the semidiplomatic edition of a record of successions from Catalão-Go, dating from 1851 and published by Pires (2015). The purpose of this research was to analyze the graphical variation present in the documents referred to, comparing them with presentations written in normative instruments of writing from that time, like the dictionaries of Bluteau (1712-1728) and Moraes Silva (1813), in order to verify the consonance, or not, between the corpus and the dictionaries. Firstly, we collected all the vocabulary with graphic variations, specifically, vocalic and consonantal. After collection, their
\end{abstract}

\footnotetext{
* Graduanda do curso de Letras/Português, Unidade Acadêmica Especial de Letras e Linguística, Universidade Federal de Goiás, Catalão, GO, Brasil; cffelicio4@gmail.com

** Docente do Programa de Pós-Graduação em Estudos da Linguagem da Unidade Acadêmica Especial de Letras e Linguística, Universidade Federal de Goiás, Catalão, GO, Brasil; vrdxavier@gmail.com
} 
spellings were checked in the mentioned dictionaries, and then we checked their etymologies in the dictionaries of Machado (1977) and Cunha (1986). Finally, we performed quantitative and qualitative analysis of the variants, based on the works by authors such as Coutinho (1976), Williams (1975) and Teyssier (1997).

Keywords: History of the Portuguese Language. Graphic variations. Philology.

\section{INTRODUÇÃo}

A Filologia é uma ciência que tem como objeto de estudo, conforme afirma Santiago-Almeida (2011, p. 2), os textos escritos, sejam eles literários ou não-literários, e possibilita estudos de extrema importância, já que a partir dos seus postulados é possível editar manuscritos antigos de maneira fidedigna, conservando, em sua transcrição, o máximo possível, suas formas originais, e com isso podemos realizar estudos em diversas esferas, e, dentre elas, a ortográfica. Os documentos que constituem o corpus desta investigação, por exemplo, já foram estudados em perspectiva léxico-cultural.

Por meio da escrita, a sociedade é capaz de fazer diversos registros de cultura, história e aspectos socioeconômicos. Esses registros escritos nos permitem analisar a escrita de determinada época e assim levantar hipóteses sobre as maneiras de grafar as palavras. Isso posto, a proposta deste trabalho é compreender uma parcela da história da Língua Portuguesa usada em Goiás, observando a grafia utilizada em manuscritos dos séculos XVIII e XIX, já editados. Mais especificamente, a proposta é analisar quantitativa e qualitativamente as variações grafemáticas - vocálicas e/ou consonantais, e seus subtipos - encontradas no corpus, à luz de instrumentos normatizadores $^{1}$ da escrita, tais como dicionários.

O corpus é composto por quarenta (40) cartas escritas durante o século XVIII, precisamente nos anos de 1751 e 1752, na Capitania de Goiás, sendo trinta (30) delas destinadas ao Rei Dom José I, nove (9) ao secretário de estado Diogo de Mendonça Corte Real e uma (1) à Secretaria de Estado da Marinha e Ultramar. As edições facsimilar e semidiplomática das cartas encontram-se disponíveis em Xavier (2012).

Também faz parte do corpus a edição semidiplomática de um processo de partilha e inventário de bens, redigido durante o ano de 1851, no povoado da Vila de Catalão, que se encontra disponível em Pires (2015). O manuscrito conta com quarenta e quatro (44) fólios, escritos pelo então escrivão Camillo José de Oliveira Novaes, que apresenta a partilha da herança de Claudio Francisco Ferreira.

Além da proposta de analisar as variações gráficas presentes no corpus, temos como objetivos verificar se há uma tendência maior à conservação da forma etimológica dos vocábulos do que uma simplificação gráfica devido a uma possível influência da modalidade oral da língua ${ }^{2}$. Além disso, cumpre observar se há

\footnotetext{
${ }^{1}$ Entende-se que os dicionários, em certa medida, registravam um padrão de escrita da época. Com isso, não se supõe que os escribas consultassem tais obras de referência. O que se pretende, nesse estudo, é verificar se a escrita observada no corpus ressoa nos dicionários.

${ }^{2}$ Convém esclarecer que, embora se compreenda que a modalidade escrita da língua não é um reflexo da sua forma oral, admite-se que, em virtude da ausência de um acordo ortográfico vigente à época, haja vestígios da oralidade nos textos em estudo.
} 
continuidade entre os períodos ortográficos da língua portuguesa nas práticas de escrita em estudo.

Para que se realizasse a pesquisa, foi feita a coleta de todos os vocábulos que apresentassem variações grafemáticas (vocálicas e consonantais) e, em seguida, o cotejo da grafia desses vocábulos nos dicionários de Bluteau (1712-1728) e Moraes Silva (1813). Também realizou-se a verificação da etimologia dos vocábulos nos dicionários de Cunha (1986) e Machado (1977). Por fim, os vocábulos foram analisados mediante a periodização da ortografia feita por Coutinho (1976) e com base em autores como Williams (1975) e Teyssier (1997), que apresentam possíveis explicações para as ocorrências de variações gráficas na história da Língua Portuguesa.

\section{BREVE CONTEXTUALIZAÇÃO E DESCRIÇÃO DO CORPUS}

Buscando atender ao objetivo de se compreender uma parte da grafia da Língua Portuguesa utilizada em Goiás, selecionaram-se documentos manuscritos dos séculos XVIII e XIX redigidos no estado em questão. Como dito anteriormente, o corpus é composto por cartas do século XVIII e um auto de partilha do século XIX, sendo tal recorte cronológico o principal critério para a seleção do corpus deste trabalho. O ideal para o cotejo das variantes gráficas seria que os documentos fossem da mesma espécie documental, mas os manuscritos de Goiás que já se encontram editados ${ }^{3}$ não o são.

Os documentos manuscritos ${ }^{4}$ que compõem o corpus apresentam uma diferença de cem (100) anos, possibilitando analisar a escrita de determinada época e verificar o que se perpetua ou não de um século para o outro. Outro critério adotado para seleção do corpus deve-se ao fato de as autoras responsáveis pelas edições, Xavier (2012) e Pires (2015), utilizarem os mesmos critérios para a edição conservadora dos manuscritos, disponíveis em Megale e Toledo Neto (2005).

Os documentos do século XVIII possuem características de carta "documento não diplomático, mas de desenho, mais ou menos padronizado, informativo, ascendente, descendente, conforme o caso." (Belloto, 2002, p. 51). São de esfera administrativa e "em geral, ascendentes, pois seus destinatários são hierarquicamente superiores ao remetente.” (Xavier, 2012, p. 30).

As quarenta (40) cartas que compõem o corpus datam dos anos de 1751 e 1752. No início da década de 50 do século XVIII, ainda período colonial, "vigorava no Brasil o chamado Governo Geral, que pôs fim ao sistema de Capitanias hereditárias e visava assegurar a posse de terra e resguardar os interesses econômicos da Coroa." (Xavier, 2012, p. 21).

\footnotetext{
3 Os integrantes do Laboratório de Estudos do Léxico, Filologia e Sociolinguística (LALEFIL), da Universidade Federal de Goiás/Regional Catalão, por meio de projetos de pesquisas, já realizaram a edição semidiplomática de um número considerável de documentos manuscritos do estado de Goiás. Convém ressaltar, porém, que ainda não foi realizada a edição de documentos da mesma espécie documental, redigidos em séculos diferentes.

${ }^{4}$ Este trabalho é resultado de uma pesquisa desenvolvida pela aluna como bolsista de Iniciação Científica na Universidade Federal de Goiás/Regional Catalão, no período 2017-2018, razão pela qual optou-se por um cotejo das variantes em documentos manuscritos goianos já editados e considerados fidedignos, porque editados por membros do Grupo de Estudos e Pesquisas em História do Português (GEPHPOR), do qual também fazemos parte.
} 
Com relação ao contexto histórico de produção das cartas, conforme aponta Xavier (2012, p. 28), era um "período de grande pujança econômica da Capitania goiana, situando-se durante o ciclo do ouro". Em decorrência da descoberta do ouro e o consequente povoamento da região, "surgiram os arraiais, onde se estabeleceram também algumas propriedades comerciais, resultando na criação de um mercado interno e urbano, que promoveu um considerável progresso e urbanização da região." (Xavier, 2012, p. 26).

As cartas, na época em questão, possibilitavam a comunicação das Capitanias com a Coroa, tratando dos mais diversos assuntos referentes à "sociedade, à religião, à política, à Justiça, à economia, dentre outros.” (Xavier, 2012, p. 28).

O documento do século XIX, redigido em Catalão no ano de 1851, é um auto de partilha, de natureza processual, que tem "como principal propósito dispor em rol o patrimônio deixado em herança por um defunto e a realização da partilha entre os seus herdeiros de direito." (Pires, 2015, p. 30). De acordo com Pires (2015, p. 31), os principais componentes dos autos de partilha são: o testamento que "descreve e avalia os bens", os inventários com a descrição de todos os bens e a partilha, "que finaliza o processo, que acontece com o aquinhoamento dos bens entre os sucessores de direito".

Conforme Pires (2015, p. 24), "Catalão foi popularizada em decorrência do movimento do ouro que ocorria em Goiás com as bandeiras", mas a região não se revelou uma terra aurífera. Sendo assim, configurou-se "como um estratégico itinerário para as outras regiões onde havia minas e para a capital da Capitania durante as primeiras décadas de setecentos." (Pires, 2015, p. 24). A autora aponta que alguns fazendeiros da região começam a fazer doações de suas terras para a construção de uma capela para atrair moradores, o que contribuiu para o surgimento de "comunidades, armazéns e vendas que alçam o início da formação de um povoado." (Pires, 2015, p. 25). Com um desenvolvimento rápido, em 1851, a região já havia passado da condição de arraial para vila, sendo chamada de Vila do Catalão.

O fato de os manuscritos pertencerem a espécies documentais diferentes não causou prejuízos à na análise dos vocábulos com variações gráficas, pois ambos apresentam características de documentos oficiais, pertencentes à esfera administrativa.

\section{Metodologia}

Para que os objetivos da pesquisa fossem atingidos, fez-se necessário realizar, primeiramente, o levantamento de todos os vocábulos que apresentassem variações grafemáticas, o qual foi feito manualmente, tendo em vista tratar-se de edições semidiplomáticas, que mantêm vocábulos escritos juntos conforme os documentos originais etc. Os vocábulos foram classificados de acordo com a caracterização das variações vocálicas e consonantais feita por Santos:

Em relação à representação gráfica de segmentos e sequências vocálicas, levamos em consideração as variações dos grafemas a por e, e por i, i por $\mathbf{e}, \mathbf{o}$ por $\mathbf{u}, \mathbf{u}$ por $\mathbf{o}, \mathbf{u}$ por $\mathbf{i}$; dos ditongos nasais finais; das letras ditas ramistas (u e v, i e j, com valores vocálicos); das semivogais. Sobre as representações gráficas das consoantes e das sequências consonantais, observaremos as variações gráficas entre $\mathbf{s , z} / \mathbf{c}, \mathbf{s}$ e ç, $\mathbf{z}$, as variações no 
uso do $\mathbf{h}$, das consoantes geminadas, uso de consoantes duplas em palavras de origem latina, da formação de sílabas por metátese e hipértese. (Santos, 2006, p. 128, grifos da autora).

A categorização de variações gráficas proposta por Santos (2006) apresenta uma delimitação do fenômeno que parece atender satisfatoriamente aos objetivos deste estudo. Porém, não nos restringimos a essa categorização, reformulando-a quando se fez necessário. Sendo assim, além das categorias de variações propostas pela autora, acrescentamos às variações consonantais a do uso de 'co' por 'qu', a qual ocorreu apenas no vocábulo cincoenta, que obteve uma frequência significativa no auto de partilha, a saber, de cinquenta e cinco (55) ocorrências, enquanto nas cartas houve somente cinco (5) casos.

À medida que iam sendo coletados, os vocábulos eram distribuídos nas suas respectivas categorias de variação. Como exemplificação, tomemos o vocábulo dous, referente à variação de ' $u$ ' por 'i', que foi encontrado no códice do século XVIII: dous (18) $(72,268,269,422,477,800$...), sendo dezoito (18) o seu número de ocorrências total e os números subsequentes referentes à sua localização neste códice, que nesse caso foi feita pela numeração das linhas. Já a indicação da localização dos vocábulos encontrados no documento do século XIX foi feita através do recto (r.) e do verso (v.) do fólio ${ }^{5}$, como mostra o exemplo a seguir: villa (30) (1r., 4r., 5r., 5v., 6r., ...).

Depois da coleta e categorização dos vocábulos, realizou-se a sua atestação gráfica nos dicionários de Bluteau (1712-1728) e Moraes Silva (1813), a fim de observar a concordância ou não entre eles e as formas gráficas das entradas contidas nestes. As obras lexicográficas citadas acima foram escolhidas porque as datas de suas publicações são coetâneas às datas de registro dos manuscritos que compõem o corpus. Feita a atestação da grafia, verificou-se a etimologia dos vocábulos nos dicionários de Cunha (1986) e Machado (1977) para comprovar se as variações encontradas podem ser explicadas ou não por sua origem etimológica.

Após estas etapas, iniciou-se a análise dos dados a partir de leituras específicas sobre a ortografia da língua portuguesa e considerando correlação dos dados com as formas gráficas encontradas em dicionários da época.

A fim de realizar o que propõe a pesquisa, mostrou-se de grande valia a caracterização, feita por Coutinho (1976), dos períodos da ortografia da língua portuguesa, sendo eles: o período fonético, o período pseudoetimológico e o período simplificado. Essa divisão cronológica é importante para que possamos verificar se há na grafia do corpus a perpetuação de características dos períodos ortográficos referidos. Além disso, as obras de Williams (1975), Teyssier (1997) e Monte (2007) muito contribuíram com relação às informações sobre a história da língua portuguesa e às explicações sobre algumas variações.

\section{RESUltados}

A apresentação dos resultados encontrados será feita em tópicos para sua melhor compreensão. Primeiramente, serão apresentados os vocábulos referentes ao

\footnotetext{
${ }^{5}$ No auto de partilha analisado, não houve numeração das linhas em sua edição, diferentemente do que se observou nas cartas do século XVIII.
} 
documento do século XVIII, especificando-se a quantidade de variações vocálicas e consonantais, bem como seus subtipos. Em seguida, mencionaremos a quantidade de vocábulos com variações que tiveram a sua grafia e etimologia atestadas nos dicionários já mencionados. Os mesmos procedimentos serão feitos com o documento do século XIX.

Além disso, será mencionada a quantidade de vocábulos que apresentaram grafias idênticas às das suas respectivas entradas nos dicionários consultados e a quantidade daqueles que tiveram sua grafia justificada pela etimologia. Tanto nos dicionários gerais, de Bluteau (1712-1728) e Moraes Silva (1813), quanto nos etimológicos, de Cunha (1986) e Machado (1977), os vocábulos que não se encontravam registrados em uma das obras, constavam na outra. Por exemplo, o vocábulo exploraçaõ está registrado em Moraes (1813), mas não em Bluteau (17121728); a etimologia de capitaçaõ consta em Cunha (1986), conquanto não em Machado (1977).

É importante salientar que quando as variações aconteceram nas formas flexionadas dos vocábulos, não se realizou a atestação gráfica nos dicionários mencionados acima, já que os mesmos registram apenas os nomes no singular e os verbos no infinitivo como entradas. Ressalta-se, ainda, que não foram considerados os textos das acepções no caso dos dicionários de Bluteau (1713-1728) e Moraes Silva (1813), mas apenas em Cunha (1986) e Machado (1977), tendo em vista a preocupação do trabalho com a forma gráfica e não com as acepções dos verbetes.

\subsection{As variações consonantais e vocálicas nas cartas que constituem o corpus}

Ao todo, foram encontrados mil e vinte e cinco (1.025) vocábulos com variação vocálica e consonantal no documento. Desse total, seiscentos e vinte e cinco (625) correspondem às variações consonantais. Cento e oitenta e quatro (184) vocábulos correspondem ao subtipo de variação entre 's' e ' $z$ ', noventa e nove (99) entre 'c' e 's', onze (11) entre 'c' e 'ç' e quatro (4) entre 'ç' e 's'. As variações no uso de consoantes geminadas - consoantes iguais que aparecem duplicadas -, consoantes duplas sequência de consoantes diferentes - e do ' $h$ ' tiveram, respectivamente, cento e noventa e cinco (195), sessenta e sete (67) e cinquenta e oito (58) ocorrências. A formação de sílabas por metátese foi observada em seis (6) vocábulos e o uso de 'co' por 'qu' contou com apenas uma (1) ocorrência.

Nos documentos em análise, constatamos a presença de quatrocentos (400) vocábulos com variações vocálicas. Os subtipos de variação 'e' por 'i', 'o' por 'u', 'u' por ' $i$ ', 'a' por 'e' e 'i' por 'e' obtiveram, respectivamente, vinte e cinco (25), dezessete (17), quatorze (14), duas (2) e uma (1) ocorrências. Não houve nenhum caso de variação de 'u' por 'o'. A variação nos ditongos nasais finais obteve cento e noventa e três (193) ocorrências. A variação com o uso do ' $y$ ' em lugar de 'i' contou com cento e trinta e quatro (134) casos e as letras ramistas com quatorze (14).

Todos os vocábulos que apresentaram alguma variação vocálica ou consonantal tiveram as suas grafias verificadas nos dicionários de Bluteau (1712-1728) e Moraes Silva (1813). Do total de seiscentos e vinte e cinco (625) vocábulos com variações consonantais, $76 \%$ foram registrados pelos dois dicionários, enquanto que dos quatrocentos (400) vocábulos com variações vocálicas, $57 \%$ foram encontrados nos dicionários. 
A tabela a seguir apresenta o número total de vocábulos com variações em cada categoria e, também, o total de vocábulos encontrados nos dicionários, seguido pela quantidade de entradas neles contidas com grafias iguais às das cartas.

Tabela 1 - Cotejo das variantes gráficas dos documentos do século XVIII em Bluteau (1712-1728) e Moraes Silva (1813).

\begin{tabular}{ccccc} 
Variação & $\begin{array}{c}\text { Total de } \\
\text { variantes } \\
\text { gráficas }\end{array}$ & $\begin{array}{c}\text { Total de } \\
\text { vocábulos } \\
\text { dicionarizados }\end{array}$ & $\begin{array}{c}\text { Formas gráficas } \\
\text { atestadas em } \\
\text { Bluteau } \\
(1712-1728)\end{array}$ & $\begin{array}{c}\text { Formas gráficas } \\
\text { atestadas em } \\
\text { Moraes Silva } \\
\text { (1813) }\end{array}$ \\
\hline 'a' por 'e' & 2 & 2 & 0 & 0 \\
'e' por 'i' & 25 & 19 & 5 & 4 \\
'i' por 'e' & 1 & 1 & 1 & 1 \\
'o' por 'u' & 17 & 2 & 0 & 0 \\
'u' por 'i' & 14 & 14 & 8 & 8 \\
'i' por 'y' & 134 & 109 & 29 & 7 \\
Ditongo Nasal final & 193 & 71 & 70 & 62 \\
Letras Ramistas & 14 & 11 & 0 & 0 \\
's/z' & 184 & 150 & 9 & 1 \\
'c/s' & 99 & 15 & 0 & 0 \\
'c/ç' & 11 & 11 & 0 & 0 \\
's/ç' & 4 & 4 & 0 & 0 \\
Uso do 'h' & 58 & 51 & 0 & 0 \\
Cons. Geminadas & 195 & 173 & 140 & 132 \\
Cons. Duplas & 67 & 67 & 38 & 32 \\
Metátese & 6 & 6 & 1 & 1 \\
'co' por 'qu' & 1 & 1 & 1 & 1 \\
\hline Total & 1.025 & 707 & 302 & 249
\end{tabular}

Percebe-se que as variações com ocorrências de ditongo nasal final, o uso do grafema ${ }^{6}$ 'h', consoantes geminadas e duplas, e uso de 'co' em contextos de 'qu' são as que apresentaram maior quantidade de vocábulos com grafias iguais às dos dicionários. Considerando a quantidade de vocábulos dicionarizados em Bluteau (1712-1728) ${ }^{7}$, observa-se que $43 \%$ possuem grafias iguais às das entradas deste dicionário, revelando que há certa uniformização na escrita das cartas do século XVIII, pois como não havia uma ortografia oficial vigente, é compreensível que parte das grafias não correspondam às registradas nos dicionários. As variações de 'a' por 'e', 'o' por 'u', letras ramistas e entre as consoantes 'c', 'ç' e 'ss', não contaram com nenhum vocábulo de grafia igual nos dicionários.

Os vocábulos com variações encontrados no manuscrito do século XVIII tiveram a sua etimologia verificada, primeiramente, no dicionário de Cunha (1986), cuja atestação contou com quatrocentos e oitenta e dois (482) vocábulos referentes às variações consonantais e duzentos e trinta e um (231) referentes às variações vocálicas.

Já no dicionário de Machado (1977), foram atestadas as etimologias de quatrocentos e quarenta e três (443) vocábulos com variação consonantal e de

\footnotetext{
${ }^{6}$ Borba (1976, p. 56) define o grafema como "a representação visual dos sons: é a contraparte escrita do fonema. Ex.: port. p, b, m são grafemas dos fonemas $/ \mathrm{p} /, / \mathrm{b} /, / \mathrm{m} /$ ".

${ }^{7}$ Foi considerado, como base para o estabelecimento das percentagens de ocorrências das variações nos dicionários, aquele em que houve maior quantidade de grafias em suas entradas idênticas às dos vocábulos contidos no corpus.
} 
duzentos e cinquenta e um (251) com variação vocálica. As diferenças na quantidade de vocábulos de um dicionário para outro referem-se ao fato de a etimologia de alguns vocábulos não se encontrar registrada, como o vocábulo sismeyros, para o qual o dicionário de Cunha (1986) apresenta a etimologia, enquanto que o dicionário de Machado (1977) não.

A tabela abaixo apresenta a quantidade total de vocábulos com variações vocálicas e consonantais coletados das cartas do corpus, a quantidade desses vocábulos que tiveram suas grafias atestadas nos dois dicionários, seguida pelo número de grafias que se correlacionam com sua etimologia.

Tabela 2 - Cotejo das variantes gráficas dos documentos do século XVIII em Machado (1977) e Cunha (1986) e quantidade de grafias etimológicas.

\begin{tabular}{ccccc} 
Variação & $\begin{array}{c}\text { Total de } \\
\text { variantes } \\
\text { gráficas }\end{array}$ & $\begin{array}{c}\text { Formas gráficas } \\
\text { atestadas em } \\
\text { Machado } \\
(1977)\end{array}$ & $\begin{array}{c}\text { Formas gráficas } \\
\text { atestadas em } \\
\text { Cunba } \\
(1986)\end{array}$ & $\begin{array}{c}\text { Total de } \\
\text { grafias } \\
\text { etimológicas }\end{array}$ \\
\hline 'a' por 'e' & 2 & 2 & 2 & 0 \\
'e' por 'i' & 25 & 19 & 19 & 1 \\
'i' por 'e' & 1 & 1 & 1 & 0 \\
'o' por 'u' & 17 & 2 & 3 & 2 \\
'u' por 'i' & 14 & 11 & 9 & 0 \\
'y' por 'i' & 134 & 93 & 90 & 4 \\
Ditongo nasal final & 193 & 111 & 95 & 67 \\
Letras ramistas & 14 & 12 & 12 & 0 \\
's' 'cz' & 184 & 140 & 144 & 0 \\
'c'/'s' & 99 & 14 & 15 & 0 \\
'c'/'ç' & 11 & 11 & 13 & 0 \\
'ç'/'s' & 4 & 4 & 4 & 0 \\
Uso do 'h' & 58 & 48 & 51 & 24 \\
Cons. Geminadas & 195 & 155 & 183 & 114 \\
Cons. Duplas & 67 & 64 & 65 & 50 \\
'co' por 'qu' & 1 & 1 & 1 & 0 \\
Metátese & 6 & 6 & 6 & 0 \\
\hline Total & 1.025 & 694 & 713 & 261
\end{tabular}

Levando-se em conta o total de vocábulos atestados no dicionário de Cunha $(1986)^{8}$, observa-se que $36 \%$ das variações podem ser explicadas com base na sua etimologia. As variações consonantais que apresentam relação com sua origem etimológica são: o uso do ' $h$ ', de consoantes geminadas e duplas. Das variações vocálicas, a ditongação nasal final é a que apresenta maior número de vocábulos com grafias etimológicas.

\subsection{As variações vocálicas e consonantais no auto de partilha de 1851}

Com relação ao manuscrito do século XIX, obteve-se o total de trezentos e quarenta (340) vocábulos com variações vocálicas e consonantais. Desse total, 62\% correspondem às variações consonantais, sendo que o uso de consoantes geminadas e

\footnotetext{
8 A preferência por esse dicionário para a elaboração das percentagens de dados verificados nos dicionários etimológicos decorreu do fato de ele conter o maior número de vocábulos nele lematizados.
} 
duplas obteve, respectivamente, sessenta e nove (69) e quarenta e cinco (45) ocorrências. As variações entre ' $s$ ' e ' $z$ ' contaram com trinta e nove (39) vocábulos, entre 'c' e 's', vinte e oito (28) e entre 'ss' e 'c', dezesseis (16). O uso do 'h' e de 'co' por 'qu' totalizaram, nesta ordem, quatorze (14) e um (1) casos. Não houve nenhuma ocorrência de vocábulos com metátese ou hipértese.

As variações vocálicas aparecem em $38 \%$ dos vocábulos, dos quais sessenta e um (61) correspondem aos ditongos nasais finais, trinta e seis (36) ao uso de 'e' em contextos de 'i' e doze (12) ao uso de 'o' em contexto de 'u'. As variações no uso do ' $y$ ', das letras ramistas, dos grafemas 'a' por 'e' e 'u' por 'i' ocorreram, respectivamente, em oito (8), seis (6), três (3) e dois (2) vocábulos.

Do total de variações encontradas no auto de partilha, 65\% das vocálicas e $81 \%$ das consonantais tiveram suas grafias registradas nos dicionários de Moraes Silva (1813) e Bluteau (1712-1728). A tabela a seguir indica a quantidade total de vocábulos conforme o tipo de variação, bem como a quantidade deles encontrada nos dicionários, seguida pelo número de grafias iguais às entradas em cada um dos dicionários.

Tabela 3 - Cotejo das variantes gráficas do documento do século XIX em Bluteau (1712-1728) e Moraes Silva (1813).

\begin{tabular}{ccccc} 
Variação & $\begin{array}{c}\text { Total de } \\
\text { variantes } \\
\text { gráficas }\end{array}$ & $\begin{array}{c}\text { Total de } \\
\text { vocábulos } \\
\text { dicionarizados }\end{array}$ & $\begin{array}{c}\text { Formas gráficas } \\
\text { atestadas em } \\
\text { Blutean } \\
(1712-1728)\end{array}$ & $\begin{array}{c}\text { Formas gráficas } \\
\text { atestadas em } \\
\text { Moraes Silva } \\
\text { (1813) }\end{array}$ \\
\hline 'a' por 'e' & 3 & 3 & 0 & 0 \\
'e' por 'i' & 36 & 30 & 3 & 3 \\
'o' por 'u' & 12 & 2 & 2 & 2 \\
'u' por 'i' & 2 & 2 & 1 & 1 \\
'i' por 'y' & 8 & 8 & 2 & 2 \\
Dint. Nasal Final & 61 & 27 & 27 & 25 \\
Letras Ramistas & 6 & 6 & 0 & 0 \\
's/z' & 39 & 37 & 0 & 0 \\
'c/s' & 28 & 21 & 0 & 7 \\
'ss/c' & 16 & 13 & 7 & 7 \\
Uso do 'h' & 14 & 9 & 7 & 35 \\
Cons. Geminadas & 69 & 55 & 34 & 14 \\
Cons. Duplas & 45 & 40 & 14 & 1 \\
'co' por 'qu' & 1 & 1 & 1 & 97 \\
\hline Total & 340 & 254 & 98 &
\end{tabular}

Dos duzentos e cinquenta e quatro (254) vocábulos que foram registrados, $38 \%$ apresentam grafias iguais às dos dicionários. Com exceção das variações entre as consoantes 's' e ' $z$ ' e 'c', 'ç' e 'ss', as variantes consonantais demonstraram maior consonância com as grafias presentes nas entradas dos dicionários. Observa-se que há variações que não apresentam vocábulos com grafia igual à dos dicionários. Contudo, é possível dizer que há certa regularidade na escrita. Se não houvesse esta regularidade, seria maior o número de vocábulos com grafias diferentes das encontradas nos dicionários.

Com relação à verificação etimológica dos vocábulos, foi realizada primeiramente no dicionário de Cunha (1986), no qual foi possível averiguar a etimologia de oitenta e três (83) vocábulos com variações vocálicas e cento e setenta e 
quatro (174) com variações consonantais. Já no dicionário de Machado (1977), oitenta e nove (89) das variantes vocálicas e cento e sessenta e uma (161) das variantes consonantais tiveram a sua etimologia verificada. A tabela abaixo exibe o total de vocábulos conforme o tipo de variação, a quantidade destes que tiveram suas grafias atestadas em cada um dos dicionários e o total deles cujas grafias são justificadas pela etimologia.

Tabela 4 - Cotejo das variantes gráficas do documento do século XIX em Machado (1977) e Cunha (1986) e quantidade de grafias etimológicas.

\begin{tabular}{ccccc} 
Variação Gráfica & $\begin{array}{c}\text { Total de } \\
\text { variantes } \\
\text { gráficas }\end{array}$ & $\begin{array}{c}\text { Formas gráficas } \\
\text { atestadas em } \\
\text { Machado } \\
(1977)\end{array}$ & $\begin{array}{c}\text { Formas gráficas } \\
\text { atestadas em } \\
\text { Cunha } \\
(1986)\end{array}$ & $\begin{array}{c}\text { Total de grafias } \\
\text { justificadas pela } \\
\text { etimologia }\end{array}$ \\
\hline 'a' por 'e' & 3 & 3 & 0 & \\
'e' por 'i' & 36 & 33 & 29 & 0 \\
'o' por 'u' & 12 & 8 & 8 & 0 \\
'u' por 'i' & 2 & 2 & 2 & 0 \\
'i' por 'y' & 8 & 6 & 3 & 1 \\
Ditongo nasal final & 61 & 31 & 33 & 0 \\
Letras ramistas & 6 & 6 & 6 & 0 \\
's'/'z' & 39 & 32 & 34 & 0 \\
'c'/'s' & 28 & 20 & 20 & 0 \\
'ss'/'c' & 16 & 14 & 14 & 0 \\
Uso do 'h' & 14 & 6 & 7 & 1 \\
Cons. Geminadas & 69 & 48 & 56 & 32 \\
Cons. Duplas & 45 & 39 & 40 & 39 \\
'co' por 'qu' & 1 & 1 & 1 & 0 \\
\hline Total & 340 & 249 & 253 & 100
\end{tabular}

Assim como no manuscrito do século XVIII, o do século XIX demonstra maior ocorrência de grafias etimológicas com as variações na ditongação nasal final e nos usos de consoantes geminadas e duplas. Observa-se que $40 \%$ das variações, a partir da atestação no dicionário de Cunha (1986), são explicadas com base em sua origem etimológica.

\section{DisCuSSÃo DOS RESUlTADOS}

\subsection{Variações correlacionadas à etimologia}

De acordo com a caracterização dos períodos ortográficos feita por Coutinho (1976), o período fonético começou com os primeiros documentos escritos em português e foi até o século XVI. Já o período denominado de pseudoetimológico teve início no século XVI e se prolongou até o ano de 1904, quando se iniciou o período simplificado, com a publicação da Ortografia Nacional de Gonçalves Viana, sendo que este se estende até os dias de hoje (Coutinho, 1976, p. 72). Conforme aponta Gonçalves (1992, p. 13), vários “estudiosos de questões ortográficas” normalmente estabelecem essa mesma periodização para a ortografia da Língua Portuguesa.

No período fonético, não havia uma padronização na escrita das palavras, já que "o objetivo a que visavam os escritores ou copistas da época era facilitar a leitura, 
dando ao leitor uma impressão, tanto quanto possível exata, da língua falada." (Coutinho, 1976, p. 72). Os textos mais antigos escritos em português comprovam essa afirmação, pois, de acordo com Gonçalves (1992, p. 31), "a prática dos escribas e dos copistas era fundamentalmente de caráter fonético, isto é, eles transcreviam, com a maior aproximação possível, a linguagem falada".

Portanto, em um mesmo documento, era possível encontrar palavras grafadas de diferentes maneiras. A autora comprova essa hipótese ao analisar as características gráficas do testamento de Afonso II, de 1214: “A palatal sonora/ž/, por exemplo, é representada, ao longo do Testamento, por $<\mathrm{I}>$ (seia, aia, seiam, etc); $<\mathrm{GI}>$ (beigio, segia , agia, etc.); $<\mathrm{G}>$ (gurge) e $<\mathrm{Y}>$ (beyio)." (Gonçalves, 1992, p. 32, grifos da autora).

Gonçalves (1992, p. 34) ressalta, ainda, que no período fonético já existia uma influência latina na grafia portuguesa, fato que começou a se intensificar com o surgimento de textos literários. O século XVI, em virtude do movimento humanista, torna-se o "marco fundamental da relatinização da língua portuguesa" (Gonçalves, 1992, p. 35).

Por conseguinte, no período pseudoetimológico, a preocupação era de se resgatar a origem das palavras, isto é, escrever conforme a sua etimologia. Segundo Coutinho (1976, p. 75), "o critério adotado pelos que seguem a grafia etimológica é respeitar, tanto quanto possível, as letras originárias da palavra". Mas, para escrever de tal maneira, era necessário que o copista tivesse um vasto conhecimento da língua, o que muitas vezes não acontecia. Por isso a denominação de pseudoetimológico, já que muitas formas eram na verdade analogias com palavras parecidas, mas sem vínculo com a sua real etimologia.

O período simplificado, conforme aponta Coutinho (1976, p. 76), é caracterizado pela necessidade de uma reforma na ortografia da língua portuguesa, oriunda da tentativa de unificar e simplificar a escrita. Houve neste período diversas discussões acerca da ortografia e propostas de vários acordos para se chegar à unificação.

A partir da verificação etimológica nos dicionários, percebe-se que algumas variações encontradas nos vocábulos são reproduções de traços antigos da escrita que foram conservados até a época em questão, o que se coaduna com a classificação proposta por Coutinho (1976) acerca da ortografia da Língua Portuguesa, enquadrando-se no período pseudoetimológico.

As variações vocálicas do corpus que podem ser explicadas com base na sua etimologia são as que utilizam o 'i' em contextos de 'e', como o vocábulo quazi e a variação de 'u' por 'i' nos vocábulos cousa e dous, sendo que os dois primeiros vocábulos citados foram encontrados nos dois manuscritos, já o último ocorreu apenas no do século XVIII. O vocábulo quazi, conforme Cunha (1986), derivou do latim quasi. Já os vocábulos cousa e dous derivaram das palavras latinas causa e duos.

Os ditongos nasais finais encontrados no corpus são representados em sua

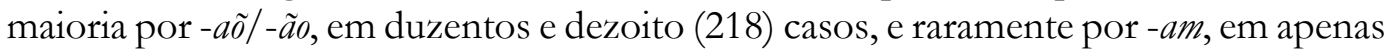
vinte e nove (29). De acordo com Teyssier (1997, p. 55), as palavras provindas do latim que terminavam em -onis, -anis e -anus convergiram para a terminação -ão na Língua Portuguesa, o que poderia explicar a grande quantidade de vocábulos grafados com essa terminação. 
Os vocábulos capitaçaõ, escrivañ e capitaõ, coletados do manuscrito do século XVIII, exemplificam essa questão, pois encontramos na obra de Cunha (1986) como suas formas etimológicas as palavras latinas capitätiō, ōnis; scriba, ānis e capitānus. O mesmo é observado com os vocábulos escrivaõ, orfã̃ e tabeliaõ do documento do século XIX, que derivaram, conforme o dicionário de Cunha (1986), das palavras latinas scriba, ānis; ŏrphănus e tabelliŏ, ōnis.

Os vocábulos probibem, extrabido, Christo, comprehendidas, contrabido e comprehencivel, do manuscrito do século XVIII, apresentam variação no uso do 'h', o que correlacionase com sua etimologia, pois, de acordo com o dicionário de Cunha (1986), são todas palavras derivadas do latim, que correspondem, respectivamente, a probibère, extrahère, christiānus, com-prehendère, contrahère e comprehēsibülis.

Além da explicação etimológica para o uso da variante citada acima, o grafema 'h' também era usado na separação das vogais em hiato, conforme aponta Coutinho (1976, p. 74, grifos do autor): "No meio das palavras, separava as vogais em hiato: cabir, sabir [...]". Verifica-se essa hipótese em vocábulos como sabir, cahir e possubir, referentes às cartas do século XVIII, que não demonstram relação com as palavras das quais derivaram. Segundo a obra de Cunha (1986), esses vocábulos derivaram das palavras latinas sătìre, cadère e possidere. Sendo assim, possivelmente o 'h' foi grafado para separar o hiato.

O uso do 'h' nos vocábulos Paranabiba, abi e dabi, presentes no manuscrito do século XIX, também ocorre em contexto de hiato. Nesse documento, o único vocábulo com uso do 'h' cuja grafia pode ser explicada pela etimologia é Christo que, conforme Cunha (1986), derivou do latim christiānus.

Vocábulos com o uso de consoantes geminadas também podem ser explicados pela influência da etimologia. É o que acontece com os vocábulos anno, villa, elle, officio, permitte, difficuldade e effeito, extraídos dos documentos setecentistas que, segundo verificou-se em Cunha (1986), derivaram das palavras latinas annum, villa, ille, officium, permittere, difficultas e effectum. Observa-se o mesmo fato com os vocábulos villa, ella, Innocencio, opposta e offerecer, encontrados no documento do século XIX, que conforme observa-se em Cunha (1986), derivam do latim villa, illa, innocentǐa, oppostus e offerescére.

Já vocábulos como rellaçaó, ditto, vallor e deffender, do manuscrito do século XVIII, e os vocábulos vallor, Donna, tutella, e vallidade, referentes ao do século XIX, não apresentam consoantes geminadas nas palavras das quais se originaram. Supostamente, foram grafadas dessa maneira por analogia com outras palavras que possuíam consoantes dobradas ou para conferir certo rebuscamento à sua grafia.

Outra variação que pode ser explicada pela etimologia é o uso das consoantes duplas, que é bastante frequente no corpus. Dentre os vocábulos coletados do manuscrito do século XVIII, temos digno, contractadores, producto e prompto, cujas etimologias encontradas em Machado (1977) foram, respectivamente, do latim dignu, contractare, producto e promptu.

O manuscrito do século XIX também apresentou vocábulos com a variação citada acima, que podem ser explicados por sua etimologia, tais como: actual, assigna, colector e escriptorio. Conforme o dicionário de Machado (1977), eles derivaram das palavras latinas actuāle, assignāre, collectōre e scriptōrius, respectivamente. No entanto, dezoito (18) vocábulos encontrados no corpus com uso de consoantes duplas não têm ligação com a sua etimologia, como no caso de saptisfeitos, vocábulo encontrado no 
documento do século XIX, que segundo Machado (1977), derivou da palavra latina satisfactus.

As ocorrências de vocábulos grafados com consoantes geminadas e duplas que não apresentaram relação com suas etimologias, provavelmente resultaram de analogia com as palavras que realmente têm explicação etimológica, gerando as formas consideradas pseudoetimológicas.

\subsection{A oscilação gráfica nas variantes presentes no corpus}

No manuscrito do século XVIII houve a ocorrência de dois vocábulos com variação no uso de 'a' e 'e': dezasseis e caudelosos. Já no manuscrito do século XVIII, os seguintes vocábulos foram coletados: desanove e desacete/desasete. Esta variação pode ter relação com o processo de dissimilação, que segundo Coutinho (1976, p. 144), consiste na "diversificação ou queda de um fonema por já existir igual ou semelhante na palavra".

Observa-se o mesmo com o uso de 'e' em contextos de 'i', que também parece ter decorrido do processo de dissimilação, resultando em uma hipercorreção por parte do copista/escriba. A hipótese é de que, ao tentar grafar as palavras da maneira mais adequada possível, o que também demonstra a tentativa de rebuscamento na escrita, atribuiu o uso do 'i' à influência da oralidade. Foi o que se observou em destrito, adquerido e fedelidade, do manuscrito do século XVIII, e edade, quaes e meretissimo do referente ao século XIX.

Os vocábulos soplicantes, fogido, morreo, pareceo e sucedeo, extraídos das cartas do século XVIII; comprir, comprio, pedio, deferio e requerio do manuscrito do século XIX, referentes ao uso de 'o' em contextos de 'u', também demonstram uma possível ligação com a hipercorreção. Possivelmente, o copista/escriba supôs que o uso de 'u', em contextos de 'o' átono, que se mostra muito comum na oralidade, não seria adequado à escrita. Apesar de a escrita e a fala "integrarem um mesmo sistema linguístico [...], não são processos idênticos, [...], existe uma forma de pronunciar que não é necessariamente igual à forma de escrever.” (Dias; Ferreira, 2015, p. 185), sendo assim, e partindo do pressuposto de que o falante reconhece que "falar e escrever são processos distintos, mas que interagem", a hipercorreção pode explicar a ocorrência de tais variações grafemáticas no corpus.

Das variações com uso de 'u' por 'i', sem levar em consideração as ocorrências que podem ser explicadas pela etimologia, temos como exemplos os seguintes vocábulos coletados do manuscrito do século XVIII: outava/oitavas, desonto/deroito e outocentas/oitocentas. Como é possível observar, as duas grafias coexistiram e provavelmente ambas eram aceitas na escrita da época, ficando a critério do copista/escriba qual usar, tendo em vista que, nas palavras de Nunes (1945, p. 76), "O ditongo ou, quer latino, quer romântico, alterna na língua moderna com or’’

Alguns dos vocábulos coletados do corpus com a variação no uso de letras ramistas (i por j, u por v), foram: Ianeyro, Iustiça e Iulho, do século XVIII; e os pares Jnventario/Inventario e Iuizo/Juizo, do século XIX. Os vocábulos dos documentos do século XVIII, representados acima, aparecem grafados apenas com 'i', não tendo havido ocorrência com uso do ' $j$ '. Já no documento do século seguinte, temos vocábulos grafados com as duas letras, 'i' e 'j', sendo que a maior frequência é dos vocábulos com 'j'. No alfabeto latino, as vogais 'i' e 'u', conforme pontua Santos (2006, 
p. 135), eram usadas tanto com valor vocálico quanto consonantal, o que justifica tal

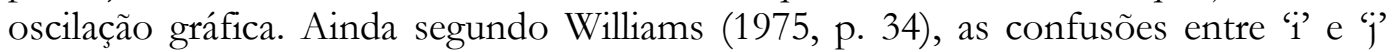
datam desde o período fonético da ortografia da língua portuguesa. Também é possível que tal fenômeno tenha se difundido por uma tradição de escrita, em que a grafia perpetua uma convenção gráfica tácita entre os escribas da época.

A variação no uso da semivogal ocorre com a substituição de 'i' por 'y', que pode ser verificada nos seguintes vocábulos: reyno, primeyro e arrayal, referentes ao manuscrito do século XVIII; e arrayal, pay e say, do século XIX. Conforme Williams (1975, p. 34) e Coutinho (1976, p. 72), esta alternância ocorre desde o período fonético da ortografia da língua portuguesa, no qual o 'i', na maioria das vezes, vinha representado pelo 'y' e não só em casos de semivogal. No entanto, os vocábulos referidos mostram o uso do 'y' exclusivamente em posição de semivogal.

Para se compreender a oscilação entre 's' e ' $z$ ' e 'c', 'ss' e 'ç', é necessário considerar, de acordo com Monte (2007, p. 351), que o latim depositou na língua portuguesa um par de sibilantes (surda/sonora) que era representado apenas pelo grafema 's'. Mas, com o fenômeno da palatalização, um processo que ocorreu durante a formação da Língua Portuguesa, criaram-se seis novos fonemas, dentre eles destacam-se /ts/ e /dz/, que explicam a origem de um novo par de sibilantes (Monte, 2007, p. 351).

Os fonemas /ts/ (surda) e /dz/ (sonora) são africados e, inicialmente, tinham um elemento oclusivo, mas transformam-se em constritivos (Monte, 2007, p. 351). Para representar o fonema/ts/ eram utilizados os grafemas 'ç' e 'c' e, para /dz/, utilizava-se o grafema ' $z$ '. Portanto:

\footnotetext{
Além da sibilante surda herdada do Latim, /s/, e da sonora, /z/, [...] que eram articuladas como fricativas ápico-alveolares, o português arcaico passa a contar, portanto, com mais um par de sibilantes, /s/ e /z/, prédorsodentais, herdadas dos fonemas africados /ts/ e /dz/. (Monte, 2007, p. 351).
}

Até então, no português arcaico, ocorria o processo de monovalência, no qual "havia um grafema para representar cada fonema [...], os fonemas não se confundem, já que o ponto de articulação é diverso.” (Monte, 2007, p. 352). O fato de os grafemas não se confundirem também é apontado por Teyssier:

\footnotetext{
A existência dessas quatro unidades distintivas no português do século XVI não sofre dúvida. As grafias são sempre muito coerentes: encontramse somente $c$ ou c em paço, moşa, parecer, só z em coz̨er, rezãa, vežes, vaz̧io; somente -ss- em passo, disse, nosso, passar, somente -s- em coser, quiseste, casar, rosa. (Teyssier, 1997, p. 60).
}

Monte (2007, p. 353) afirma que não existiam tais confusões na representação das sibilantes na porção setentrional de Portugal, enquanto que outras regiões apresentavam confusões datadas desde o século XIII. No centro-sul de Portugal já se observavam confusões na grafia das sibilantes desde o século mencionado anteriormente, e é importante mencionar, que "o chamado português padrão originase justamente nos falares do centro-sul português, onde parece não ter se fixado durante muito tempo a distinção entre os quatro fonemas sibilantes." (Monte, 2007, p. 354). 
Uma provável justificativa, apontada por Monte (2007, p. 355), para a origem das confusões, decorre do processo de desafricamento, no qual o fonema perde o elemento oclusivo. Consequentemente, os dois pares de fonemas (/ts/ e /dz/; /s/ e $/ \mathrm{z} /$ ) "passam a ser articulados do mesmo modo (sibilantes), com pontos de articulação próximos: alvéolos e palato duro.” (Monte, 2007, p. 355). Desta forma, desde 1550 observam-se confusões na grafia, "encontra-se $c ̧$ em vez de $-s s-,-s s-$ em vez de $c$, z em vez de -s- e -s- em vez de -r-." (Teyssier, 1997).

No século XVIII, no Brasil e em Portugal, os fonemas pré-dorsodentais, /s / e $/ z /$, acabam prevalecendo, o que leva ao fenômeno de polivalência, já que um mesmo fonema pode ser representado por dois ou mais grafemas (Monte, 2007, p. 358).

As oscilações gráficas observadas no corpus demonstram essa polivalência. Há diversos vocábulos que aparecem com duas grafias, como casa/caza, fasenda/fazenda, balanca/balança e prezença/presença, coletados do manuscrito do século XVIII. No documento do século XIX, também é possível observar tal oscilação gráfica nos vocábulos casado/caz̧ado, desoito/dezoito e justiça/justica.

Percebe-se que a oscilação gráfica, provavelmente, decorreu da quantidade de grafemas disponíveis para representar o mesmo fonema. Como até o início do século XX não existia nenhum acordo ortográfico oficial, são compreensíveis tais oscilações nas grafias, até porque ainda hoje persistem dúvidas com relação ao uso dessas consoantes na escrita das palavras, já que não há regra clara na ortografia da língua com relação ao uso dos grafemas 's', 'z', 'ç' e 'ss'.

A formação de sílabas por metátese foi encontrada somente no manuscrito do século XVIII. Os vocábulos que se enquadram nesse tipo de variação são: percaução, percisos/preciso, preguntas, prometeria e pertenderam. Como houve a ocorrência de apenas seis (6) vocábulos e a frequência dos mesmos foi entre uma (1) e duas (2), a hipótese é de que o escriba tenha se baseado na sua realização oral ao grafar tais palavras, até porque, essa confusão é visível na oralidade e persiste até os dias atuais.

O vocábulo cincoenta, pertencente à variação de 'co' por 'qu', foi encontrado nos dois documentos. Segundo Williams (1975, p. 34), essa forma gráfica acontece desde o período fonético da ortografia portuguesa. Portanto, parece ter resultado do som dos grafemas dentro da palavra.

\subsection{Breves considerações sobre as variações gráficas no corpus}

Com a verificação dos vocábulos nos dicionários, é possível notar que formas gráficas que parecem incorretas nos dias atuais eram comuns nos séculos XVIII e XIX, inclusive encontrando-se registradas em dicionários da época. No manuscrito do século XVIII, as variações que mais apresentaram consonância com as grafias dos dicionários foram: o uso de 'e' em contextos de 'i', de 'u' por 'i', de ditongos nasais finais, de 'h', de consoantes geminadas, de consoantes duplas e de 'co' por 'qu', como nos exemplos a seguir: taes, geraes, pareceo, dous, outo, capitação, bum/ buma, anno, prompto e cincoenta.

No caso da variação na ditongação final, os vocábulos apresentaram, na maioria das vezes, apenas diferença na acentuação. O dicionário de Bluteau (17121728) apresenta, quase sempre o sinal gráfico indicador de fonema nasal na vogal 'o', raramente o faz na vogal 'a', enquanto o dicionário de Moraes Silva (1813), traz, em sua maioria, o sinal gráfico na vogal 'a'. 
As variações encontradas no documento do século mencionado que divergem das entradas nos dicionários são: uso das letras ramistas e entre as consoantes ' $s$ ' e $z$ ', e entre 'c', 'ç' e 'ss'. No caso da variação com uso de 'y', apenas o vocábulo ley/leys está grafado conforme os dicionários. O restante dos vocábulos com essa variação aparece grafado com a vogal 'i'.

Com o documento do século XIX, ocorre o mesmo que foi mencionado anteriormente, uma vez que as variações entre as vogais ' $u$ ' e ' $i$ ' e 'o' e ' $u$ ', os ditongos nasais finais, no uso de ' $h$ ', bem como de consoantes geminadas e duplas apresentam grafias iguais às entradas nos dicionários. Com as variações no uso de ' $y$ ', das letras ramistas e entre as consoantes 's' e ' $z$ ' e 'c', 'ç' e 'ss', não houve vocábulos com grafias idênticas às das palavras-entradas nos dicionários.

A partir do cotejo nos dicionários gerais de língua, foi possível verificar que a escrita presente no corpus demonstra relação com instrumentos normatizadores da época, e não se trata de um caos, como muitas vezes se considera. Nota-se que há regularidades na escrita, mesmo existindo situações de oscilação gráfica, por influência da oralidade ou não. Assim como defende Fachin (2011, p. 16), a partir da análise da escrita praticada no século XVIII, é possível constatar que existiam "práticas de escrita em vias de consolidar-se". Percebe-se isto com as grafias semelhantes aos dicionários de Bluteau (1712-1728) e Moraes Silva (1813), e também entre os dois manuscritos que compõem o corpus, que, apesar de uma diferença de quase 100 anos, neles encontramse grafias que se perpetuaram ao longo dos séculos, por exemplo, as variações nos ditongos nasais finais e no uso das consoantes geminadas.

É de conhecimento geral que não havia nos séculos XVIII e XIX uma ortografia oficial. Existiam, sim, as gramáticas e dicionários que tentavam normatizar a escrita, mas, mesmo assim, apresentavam divergências entre si. Conforme aponta Williams (1975, p. 41), houve no século XVIII uma crescente publicação de ortografias que buscavam padronizar a escrita, o que mostra a preocupação em se uniformizar a grafia. Além disso, em consonância com Gonçalves (1992, p. 40):

As obras de tipo lexicográfico são da maior importância não apenas para a história do léxico, mas também no domínio da ortografia, uma vez que servem para difundir determinado uso, contribuindo, portanto para a normalização gráfica.

Portanto, é visível, assim como já demonstrou Fachin (2011), que as práticas de escrita apresentavam regularidades e semelhanças. Os manuscritos analisados são de épocas e de punhos diferentes. Entretanto, foi possível encontrar várias grafias similares entre eles, demonstrando-se que, apesar da ausência de um acordo ortográfico na época, existia uma convenção ortográfica ${ }^{9}$ que regia as práticas de escrita, uma espécie de acordo tácito entre os escribas da época.

\footnotetext{
${ }^{9}$ Entende-se que a convenção ortográfica pode ser compreendida como uma espécie de acordo tácito existente devido a uma tradição de escrita, diferentemente do acordo ortográfico, resultante de uma decisão política com vistas a institucionalizar uma norma de escrita.
} 


\section{CONCLUSÃo}

A partir do levantamento e análise dos dados, é possível constatar que existe a tentativa de conservação das escritas latinas e gregas, que se observa nas grafias etimológicas, principalmente, nas variações com uso do ' $h$ ' e na presença de consoantes geminadas e duplas. Ao mesmo tempo, percebe-se que há a reprodução das escritas pseudoetimológicas, também observadas nas variações já citadas, buscando-se uma escrita mais rebuscada.

Observa-se que existem grafias que podem ser decorrentes da influência da oralidade, especialmente nas variações vocálicas e na formação de sílaba por metátese. A influência da oralidade nestas realizações também é frequente nos dias de hoje, o que pode ser resultado da hipercorreção, a qual pode ser concebida como "uma variação motivada pelo zelo excessivo com o registro formal e pelo desconhecimento das condições de emprego de formas características desse registro" (Mourão, 2010, p. 174).

Com base nos resultados obtidos, certifica-se que, apesar de os documentos pertencerem ao período pseudoetimológico da ortografia da língua portuguesa, existem resquícios do período fonético. Conforme aponta Williams (1975, p. 39), o uso de determinadas consoantes dobradas, como 'll', no período fonético, voltava-se para a finalidade de diferenciar o som de 'l', mas com a ampla divulgação das escritas etimológicas, o uso do grafema 'l' passou a ser relacionado com a sua etimologia e, em muitas palavras, usado de maneira inadequada.

Compreende-se, com os resquícios do período fonético e as características do período pseudoetimológico presentes no corpus, que a escrita de determinado período não é marcada apenas por particularidades de sua época, mas pode demonstrar traços de outros períodos, que se perpetuam ao longo dos séculos, pois não há ruptura, mas um continuum entre eles.

Não é possível saber qual o grau de escolaridade dos escribas/copistas dos manuscritos analisados. Mesmo assim, a partir dos dados é possível constatar que eles, apesar de suas eventuais oscilações gráficas, demonstraram conhecer a grafia utilizada na época, o que se verificou a partir da presença de grafias iguais às lematizadas nos dicionários dos séculos XVIII e XIX. Portanto, havia uma norma, ainda que não oficial.

As semelhanças entre as variações gráficas nos documentos demonstram que há uma uniformização na escrita, e, como não havia uma ortografia oficial vigente no período de produção do corpus, é normal que existam grafias divergentes. Conforme afirma Fachin (2011, p. 342), "toda pessoa está sujeita a oscilações na escrita quando o assunto é ortografia, pois em muitos aspectos o conhecimento ortográfico cede espaço a dúvidas de ordem fonológica".

A consonância com instrumentos normatizadores da escrita, sejam dicionários ou gramáticas, é substancial. No século XVIII, como afirmam Williams (1975), Coutinho (1976) e Neves (2012), começam a aparecer várias gramáticas, ortografias e vocabulários com o intuito de normatizar e unificar a escrita. Estes instrumentos visavam a impor, de certa forma, um modelo de norma ortográfica. Sendo assim, vários autores influentes começam a publicar suas ortografias, a exemplo de Madureira Feijó (1861). E, assim como Faraco (2008, p. 74), concordamos que tais instrumentos normatizadores, não só em séculos passados, como atualmente, não servem apenas 
para demonstrar como se deve escrever, mas funcionam "como instrumentos de fixação de um padrão a ser tomado como regulador (normatizador)".

Os instrumentos normatizadores eram e são impostos por aqueles que possuem poder, que podem ditar como deve ser a escrita de determinada língua, e tudo o que está em desacordo é considerado erro. $\mathrm{Na}$ época do corpus, as gramáticas e dicionários, diante da ausência de uma ortografia oficial, possuíam caráter normatizador para ditar o que era considerado erro ou acerto na grafia vigente à época.

Espera-se que este trabalho possa auxiliar em uma maior compreensão acerca da grafia da língua portuguesa usada em Goiás, além de contribuir com os futuros estudos de caráter filológico e gráfico.

\section{REFERÊNCIAS}

Bellotto HL. Como fazer análise diplomática e análise tipológica de documento de arquivo. São Paulo: Arquivo do Estado e Imprensa Oficial do Estado; 2002. (Série como fazer, Vol. 8)

Borba FS. Pequeno vocabulário de linguística moderna. 2a ed. São Paulo: Companhia Editora Nacional; 1976.

Bluteau R. Vocabulario portuguez \& latino. Coimbra: Collegio das Artes da Companhia de Jesus; 1712-1728. [citado 31 jul. 2018]. Disponível em: http://www.ieb.usp.br/.

Coutinho IL. Pontos de gramática histórica. $7^{\text {a }}$ ed. rev. Rio de Janeiro: Ao livro técnico; 1976.

Cunha AG. Dicionário etimológico Nova Fronteira da língua portuguesa. $2^{\mathrm{a}}$ ed. rev. e acresc. de um supl. Rio de Janeiro: Nova Fronteira; 1986.

Dias JAFR, Ferreira EP. Desvios na escrita: projeções fonético-fonológicas ou consequências do sistema ortográfico? O ensino reflexivo da ortografia. Caderno de Letras. 2015, Jan-Jun;24:169-190. [citado 13 fev. 2019]. Disponível em:

https://periodicos.ufpel.edu.br/ojs2/index.php/cadernodeletras/article/view/7299.

Fachin PRM. Práticas de escrita setecentista em manuscritos da administração colonial em circulação pública no Brasil [tese]. São Paulo: Faculdade de Filosofia, Letras e Ciências Humanas, Universidade de São Paulo; 2011.

Faraco CA. Norma culta brasileira: desatando alguns nós. São Paulo: Parábola Editorial; 2008.

Feijó JMM. Othographia ou arte de escrever e pronunciar com acerto a lingua portugueza. Lisboa: Typografia Rollandiana; 1861.

Gonçalves MF. Madureira Feijó, ortografista do século XVIII: para uma história da ortografia portuguesa. Lisboa: Instituto de Cultura e Língua Portuguesa/Ministério da Educação; 1992. [citado 14 fev. 2019]. Disponível em:

http://www.academia.edu/6411298/Madureira_Feij\%C3\%B3_ortografista_do_s\%C3\%A9culo_XVII I._Para_uma_hist $\%$ C3\%B3ria_da_Ortografia_Portuguesa.

Machado JP. Dicionário etimológico da língua portuguesa: com a mais antiga documentação escrita e conhecida de muitos vocábulos estudados $3^{\mathrm{a}}$ ed. Lisboa: Livros Horizonte; 1977.

Megale H, Toledo Neto SA, organizadores. Por minha letra e sinal: documentos do ouro do século XVII. Cotia, SP: Ateliê Editorial/FAPESP; 2005. 
Monte VM do. Documentos setecentistas: edição semidiplomática e tratamento das sibilantes [dissertação]. São Paulo: Faculdade de Filosofia, Letras e Ciências Humanas, Universidade de São Paulo; 2007.

Moraes Silva A. Diccionario da lingua portugueza. $2^{\mathrm{a}}$ ed. Lisboa: Typographia Lacerdina; 1813. [citado 31 jul. 2018]. Disponível em: http://www.ieb.usp.br/.

Mourão E. A hipercorreção na escrita formal: dilemas do revisor de textos. SCRIPTA. 2010;14(26):163-178. [citado 08 set. 2019]. Disponível em: https://www.repositorio.ufop.br/bitstream/123456789/7534/1/ARTIGO_Hipercorre\%C3\%A7\%C 3\%A3oEscritaFormal.pdf.

Neves MHM. A gramática passada a limpo: conceitos, análises e parâmetros. São Paulo: Parábola Editorial; 2012.

Nunes JJ. Compêndio de gramática histórica portuguesa: fonética e fonologia. $3^{a}$ ed. Lisboa: Editora Clássica; 1945.

Pires MGG. De bens de herança a bens culturais: um estudo linguístico de autos de partilhas oitocentistas de Catalão-Go [dissertação]. Catalão: Unidade Acadêmica Especial de Letras e Linguística, Universidade Federal de Goiás, Regional Catalão; 2015.

Santiago-Almeida MM. Para que filologia/crítica textual?. Acta. 2011;1:1-12. [citado 31 jul. 2018]. Disponível em: http://www.assis.unesp.br/Home/SitesInternos/RevistaActa/PARAQUEFILOLOGIACRiTICATE XTUAL\%28revistoISSN\%29.PDF.

Santos MBG dos. Variação grafemática em documentos manuscritos em português durante o século XVIII [tese]. São Paulo: Faculdade de Filosofia, Letras e Ciências Humanas, Universidade de São Paulo; 2006.

Teyssier P. História da língua portuguesa. Trad. Celso Cunha. São Paulo: Martins Fontes; 1997.

Williams EB. Do latim ao português: fonologia e morfologia históricas da língua portuguesa. Trad. Antônio Houaiss. $3^{\mathrm{a}}$ ed. Rio de Janeiro: Tempo Brasileiro; 1975.

Xavier VRD. Conexões léxico-culturais sobre as minas goianas setecentistas no livro para servir no registro do caminho novo de Parati [tese]. São Paulo: Faculdade de Filosofia, Letras e Ciências Humanas, Universidade de São Paulo; 2012. 